\title{
INDICAÇÕES SOBRE A ESTRUTURA \\ DA AÇÃO ESPECÍFICA FREUDIANA: EFEITOS PARA O SUJEITO DA PSICANÁLISE
}

Ronaldo Torres

Psicanalista,

membro

participante do

Fórum do Campo

Lacaniano de São

RESUMO: Procura-se indicar como a ação específica de Freud não Paulo, mestre em Psicologia Clínica pelo Instituto de Psicologia da USP. Doutorando em Psicologia Clínica pelo Instituto de Psicologia da USP. pode corresponder à ideia de uma ação eficaz de encontro do objeto adequado ao desejo. Ao contrário, é cristalina sua construção de um modelo de funcionamento que se movimenta para o reencontro de um objeto que nunca de fato se coloca. Passaremos então a explorar os efeitos dessa ação para o sujeito, na tentativa de extrair para a tradição lacaniana consequências mais extensas advindas dessa noção.

Palavras-chave: ação específica, experiência de satisfação, desejo, demanda, transferência.

ABSTRACT: Indications on the structure of the Freud's 'specific action': effects on the psychoanalyses subject. This article points out how Freud's "specific action" cannot correspond to the idea of an effective action that guarantees the encounter with the object of desire. On the contrary, in Freud's notion of "specific action", the model of functioning turns towards a re-encounter with an object that, in fact, never comes true. We will analyse the effects of this action on the subject, in order to bring to the Lacanian tradition the more extensive consequences of this notion.

Keywords: specific action, experience of satisfaction, desire, demand, transference. 
$\mathrm{E}$ ste artigo trafega por dois propósitos. O primeiro se coloca pela recuperação do conceito de ação específica em Freud, com vistas a demonstrar por que essa noção, muito utilizada por certo pós-freudismo como índice de um suposto mecanismo de adaptação do homem a determinada realidade empírica, é, ao contrário, exatamente a estrutura que surge no texto freudiano para dar contorno à impossibilidade de haver objeto empírico adequado ao desejo. Este primeiro passo, longe de ser original, implica apenas uma posição de princípio, que reforça a necessidade de indicar como do fato de escolher entre uma clínica da adequação do sujeito a determinada concepção de realidade ou uma clínica que parte da inadequação do objeto ao desejo, se derivam consequências bem distintas, que não devem escapar às nossas considerações. Para isso será necessário que, em um primeiro momento, façamos uma retomada da noção em Freud.

Nosso segundo propósito é apontar outros desdobramentos que essa estrutura da ação específica pode nos oferecer dentro mesmo da orientação dada a este tema por Jacques Lacan. Se por um lado ele dá um passo decisivo em seu seminário sobre a ética demonstrando como a ação específica "não pode corresponder senão ao objeto reachado" (LACAN, 1959/1985, p.56) que sustenta a cadeia significante e o desejo, talvez a pouca utilização desse conceito na tradição lacaniana tenha deixado de encontrar contribuições mais amplas que podemos aí localizar para a clínica, a saber: com relação à constituição do sujeito, ao circuito da demanda, à estrutura do desejo e, por fim, à transferência.

Comecemos, então, com um retorno ao conceito em Freud.

As referências à ação específica (spezifische Aktion) remontam ao início de sua obra. Na realidade, o texto em que abordou de maneira mais sistemática essa noção foi justamente aquele que nunca foi por ele levado a público (embora escrito em 1895), localizado em meio a suas correspondências com Fliess e publicado apenas em 1950, depois de sua morte, portanto. Trata-se do manuscrito sem título que ganhou o nome de Entwurf einer Psychologie (Projeto/Esboço de uma Psicologia) na publicação em alemão e acabou transformado em "Projeto para uma Psicologia Científica”, tradução literal para o português do título da edição de Strachey. O conceito aparece também nas próprias cartas a Fliess contemporâneas aos esboços do "Projeto". Porém, embora o tratamento conceitual à ação específica tenha sido dado de forma mais consistente no "Projeto" e nas cartas a Fliess, da mesma época deste manuscrito, o termo nunca deixou de cumprir importante função nas teorizações freudianas, surgindo em diversas passagens de sua obra, mesmo que sob outras nomeações distintas ou mais genéricas. ${ }^{1}$

\footnotetext{
${ }^{1}$ Essas referências podem ser recolhidas de outro trabalho contemporâneo ao "Projeto", "Sobre os fundamentos para destacar da neurastenia uma síndrome específica denominada neurose de angústia” (1895), mas também em seus textos de meados da década de 1910,
} 
Apesar de ser notado de forma extensiva nos escritos de Freud, o conceito de ação específica não sofreu modificações em sua estrutura e função, razão pela qual o abordaremos, prioritariamente, pelo lugar por onde surgiu e recebeu tratamento mais detido, ou seja, pelo "Projeto".

Neste trabalho, no qual pretendeu estabelecer uma "psicologia para neurologistas", Freud se valeu de um princípio de inércia que orienta o funcionamento do aparelho psíquico, uma tendência neuronal de se livrar de qualquer acréscimo de energia (primeiro teorema). O aparelho nervoso seria em princípio um sistema de recepção e descarga de energia, sensorial e motor, portanto, tal como o modelo do arco reflexo. Diante de qualquer estímulo, o aparelho usa a quantidade de energia do estímulo captado pelo aparato sensorial e descarrega essa energia em forma motora, atendendo ao princípio de inércia. A essa função primária (vinculada apenas à descarga de energia) sobrevém uma secundária, que se caracteriza pela "fuga do estímulo", na qual as descargas motoras que obtêm sucesso em cessar o estímulo exógeno, a partir da fuga, "são preferidas e conservadas" (FREUD, 1895a/1987, p.316).

Todavia, e aqui começa a se inserir o conceito, que apenas parece simples, de ação específica, há também os estímulos de ordem endógena. Freud fala que tais estímulos estão ligados a Not des Lebens. Em geral, toma-se esse termo alemão por "necessidades da vida", tal como a fome, por exemplo. Entretanto, Lacan (1959/1985) chama atenção para a questão de que Not carrega uma acepção mais forte do que "as necessidades" e fala sobre o caráter de urgência refletido nesta palavra. Com efeito, além de "necessidade", encontramos as seguintes traduções para o Not alemão: “miséria”, “penúria”, “dificuldade”, “apuro”, “precisão” e "perigo" (TOCHTROP, 1968). Assim, de fato, a palavra implica uma noção mais precisa que a "necessidade", apontando para uma nuance mais aguda do termo. Isso vem ao encontro de dois pontos importantes. Em primeiro, que essa Not des Lebens parece estar ligada de forma direta ao Hilflosigkeit, ao desamparo original do humano, termo freudiano também usado no “Projeto”. E, em segundo, que tanto a Not des Lebens como o Hilflosigkeit estão ligados ao Nebenmensch, um terceiro termo usado no "Projeto", que diz respeito ao "humano ao lado". Mas vejamos com vagar como esses pontos se articulam.

Voltemos ao estímulo endógeno ligado a Not des Lebens. Diante desse tipo de estímulo, que também se manifesta por um acúmulo de energia que requisita sua descarga segundo o princípio da inércia, a fuga não é eficaz, notadamente por não conseguir afastar o estímulo. Para esses casos, Freud diz:

\footnotetext{
“Repressão" (1915) e "Os instintos e suas vicissitudes" (1915), e também em um texto tardio como "O mal-estar na civilização” (1930).
} 


\begin{abstract}
"Eles cessam apenas mediante certas condições, que devem ser realizadas no mundo externo. Para efetuar essa ação (que merece ser qualificada de "específica”), requer-se um esforço que seja independente da Qך endógena... Em consequência, o sistema nervoso é obrigado a abandonar sua tendência original à inércia. Precisa tolerar

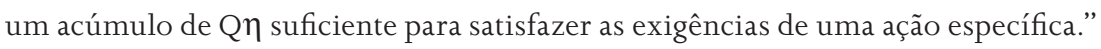
(FREUD, 1895a/1987, p.316)
\end{abstract}

Assim, a ação específica se contrapõe a um elemento central desse desenho inicial do aparelho psíquico. Em primeiro plano, se contrapõe ao próprio princípio de inércia, na medida que requisita, ao contrário da descarga imediata notada diante do estímulo externo, uma tolerância de acúmulo de energia para que a ação seja possível. Nesse mesmo sentido, se contrapõe também ao que poderia ser chamado de ações inespecíficas, ações de descarga motora que não logram êxito em se livrar do estímulo. Assim, Freud menciona certas condições que devem ser "realizadas no mundo externo" para que esse tipo de estímulo possa cessar, ações que vão além da simples descarga motora encontrada no procedimento diante de estímulos externos. Nota-se que o funcionamento do aparelho aqui é diferente porque não se trata de dispor de caminhos que são selecionados pela efetividade da resposta reflexa em afastar o estímulo (caminhos que são "preferidos e conservados"), mas de encontrar, por outro tipo de ação, um caminho de descarga da energia. Porém, a contraposição da ação específica ao princípio de inércia é ambígua, pois, se por um lado, não o atende, por outro, só o faz para poder atendê-lo.

O que temos, então, até o momento, são as quantidades que não se acumulam (Q) e as quantidades que ficam retidas no aparelho para fins de cumprir com a Not des Lebens. Freud segue postulando dois tipos de neurônios capazes de justificar essa diferença na relação com a tensão que perturba o princípio de inércia. São eles os neurônios que formam o sistema $\varphi$, que são neurônios completamente permeáveis, e os que formam o sistema $\psi$, neurônios parcialmente permeáveis. Os neurônios do sistema $\varphi$ são imutáveis, ou seja, não têm sua estrutura alterada pela passagem de excitação e sempre retornam ao mesmo estado. São os neurônios que recebem a quantidade de estímulos externos, ligados à percepção e a motricidade. Já os neurônios do sistema $\psi$, permeáveis apenas de modo parcial (barreiras de contato), são modificados pela passagem de excitação e guardam a marca da excitação: é o protótipo da memória, da representação e do pensamento definido no modelo freudiano. A diferenciação entre os neurônios, causada pela passagem da excitação, origina aqueles do sistema $\psi$ que são capazes de inscrever os efeitos dessa passagem em sua própria estrutura. Além disso, também como efeito de suas barreiras de contato (que os tornam parcialmente permeáveis), tais tipos de neurônios criam o que Freud denomina Bahnung, traduzido por "facilitação”. 
Lacan (1959/1985) propôs que a tradução mais apropriada seria a de trilhamento, porque se trata de uma ligação entre os neurônios do sistema $\psi$ a partir da

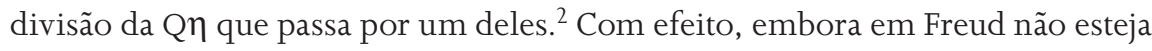
presente a ideia de uma ligação material permanente, há essa marca semelhante espalhada por determinados grupos de neurônios do sistema $\psi$ causado por certa

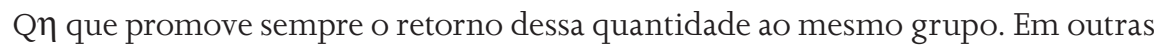
palavras, a trilha, uma vez aberta, facilita o caminho em um momento ulterior. Isso faz com que Freud afirme que "a memória está representada pelas diferenças nas facilitações entre os neurônios $\psi$ ” (FREUD, 1895a/1987, p.320). Tais Bahnungen comportam a propriedade de guardar determinada Q $\eta$ em um grupo de neurônios. Isso atende a necessidade do aparelho que deve reter Qך para fins de descarga dos estímulos endógenos, mas ao mesmo tempo, para cada neurônio, cumpre uma função de descarga imediata na medida que divide/descarrega a quantidade com aqueles do mesmo grupo. Assim, é importante notar como a memória e a representação estão sobre o regime exclusivo da quantidade no modelo freudiano, ou seja, diferentes marcas e Bahnungen correspondem a níveis

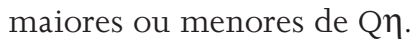

Mas além das diferenças do trilhamento nos neurônios $\psi$ que fundam a memória, Freud distingue também duas classes dentro do próprio sistema $\psi$. Os neurônios $\varphi$ que formam o sistema perceptivo e motor como vimos no cumprimento da função primária diante de estímulo externo, se ligam ao sistema $\psi$ uma vez que esse consegue reter uma imagem motora (um trilhamento) do movimento eficiente que será, como já citamos, “preferido e conservado”. Essa memória motora é típica do que Freud chamou de sistema $\psi$ do pallium. Este se trata de um subsistema mais periférico do sistema $\psi$, ligado ao sistema $\varphi$ e que recebe quantidade oriunda deste último. A outra classe dentro do sistema $\psi$ é formada pelos neurônios nucleares. Esses só recebem quantidades advindas de estímulos endógenos e, portanto, não se articulam ao sistema $\varphi$.

Esse aparato descrito por Freud pode nos introduzir aos elementos que se encontram presentes na ação específica, mas o que nos parece fundamental é que não conseguimos avançar nisso sem o que Freud chama de "experiência de satisfação". Acontece que boa parte desse aparato do aparelho psíquico retomado nos parágrafos acima é apoiada em um elemento estrangeiro ao próprio sistema. Freud afirma no "Projeto" que:

\footnotetext{
${ }^{2}$ O radical bahn do alemão, de fato, não remonta ao "fácil" ou "facilitado", mas sim ao "caminho”, “pista”, “trilha”, "passagem”, “canal”, etc. (TOCHTROP, 1968). Bahnung se refere, portanto, a "ato de abrir pista" (HANS, 1996). Facilitação estaria mais próxima do erleichterung do alemão (Dicionário Português-Alemão, 1983) e seria mais um vício da tradução para o português do inglês das Obras completas.
} 
“O organismo humano é, a princípio, incapaz de promover essa ação específica. Ela se efetua por ajuda alheia (Nebenmensch), quando a atenção de uma pessoa experiente é voltada para um estado infantil por descarga através da via de alteração interna." (FREUD, 1895a/1987, p.336)

Ou seja, a presença desse Nebenmensch ("homem/humano ao lado”, em tradução literal) é parte integrante da ação específica e ponto inicial de uma série de processos que se desenrolam a partir de então, como Freud deixa claro nas linhas seguintes:

"Quando a pessoa que ajuda executa o trabalho da ação específica no mundo externo para o desamparado, este último fica em posição, por meio de dispositivos reflexos, de executar imediatamente no interior de seu corpo a atividade necessária para remover o estímulo endógeno. A totalidade do evento constitui então a experiência de satisfação, que tem as consequências mais radicais no desenvolvimento das funções do indivíduo.” (FREUD, 1895a/1987, p.336, grifo nosso)

Assim, temos essa primeira marca importante relacionada à ação específica que nos fala de uma "totalidade do evento", que reúne em seu arcabouço o humano desamparado e o Nebenmensch, este último não dissociado do objeto capaz de atender a urgência posta pelo estímulo de ordem endógena. É só a partir daí que o aparelho pode passar a funcionar segundo as relações apontadas entre o sistema $\varphi$ e o sistema $\psi$. Freud é bastante claro neste ponto. A experiência de satisfação, com seu registro de descarga que atende ao princípio de inércia, acaba por criar uma imagem motora, ou seja, um traço mnêmico no sistema $\psi$ do pallium que registra aquela experiência. Tal registro mantém íntima relação com o sistema $\varphi$ (como já vimos, o sistema $\psi$ do pallium se relaciona sem intermediações com as quantidades de $\varphi$ ), que atende por todo o campo da percepção. Entretanto, a experiência de satisfação também cria uma memória do objeto, esta também relacionada aos neurônios $\varphi$ (percepção). Essas memórias (representações) do sistema $\psi$ do pallium criam trilhamentos (Bahnungen) com os neurônios do sistema $\psi$ nucleares, que estão ligados aos estímulos endógenos e passam a registrar também esses traços.

Os desdobramentos que se seguem à experiência de satisfação trazem uma segunda marca importante à noção de ação específica. A questão é que, uma vez já experienciada a satisfação, quando o sistema $\psi$ nuclear volta a receber quantidade ligada a Not des Lebens, reaparecendo o "estado de urgência ou desejo" (FREUD, 1895a/1987, p.337), há uma ativação da representação do objeto (lembrança) ao mesmo tempo que, devido aos trilhamentos com os neurônios do pallium, há 
ativação da imagem motora ligada à percepção (neurônios $\varphi$ ), reconstruindo a presença do objeto a partir de uma alucinação:

"Não tenho dúvida de que na primeira instância essa ativação do desejo produz algo idêntico a uma percepção - a saber, uma alucinação. Quando uma ação reflexa é introduzida em seguida a esta, a consequência inevitável é o desapontamento." (FREUD, 1895a/1987, p.337)

Dessa maneira, depois da experiência de satisfação associada, como vimos, ao Nebenmensch, forma-se um circuito primeiro de Bahnungen no aparelho dirigido à tentativa de satisfação alucinatória diante do desejo. Freud nomeia esse funcionamento de "processo primário”. "Primário” porque primeiro. Na sequência da citação acima, Freud diz que o que se segue à alucinação é uma ação reflexa que desemboca necessariamente no desapontamento. Acontece que as ações relacionadas à presença do objeto não conseguem diminuir o estado de tensão porque o objeto não está em realidade presente. Mas se houver presença real do objeto, qual é seu estatuto?

Essa questão é fundamental porque, para Freud, não há funcionamento do aparelho em paralelo à experiência de satisfação — ao contrário, o modelo se apoia em uma experiência original que funda o funcionamento primeiro do aparelho. Ou seja, sem a experiência original de satisfação vivida como uma "totalidade do evento" que inclui o "humano ao lado", o aparelho não funcionaria da forma como o faz. Além disso, o processo secundário (do qual falaremos à frente), que vem se articular ao processo primário no aparelho, não pode ser concebido de forma autônoma deste último e é, portanto, também apoiado na mesma experiência. Isso nos mostra que não importa o que aconteça no processo secundário, o estatuto do objeto para Freud é sempre o de ser reencontrado, isto é, vinculado de forma estrutural à experiência original.

O processo secundário é postulado por Freud no "Projeto" para que seja possível uma diferenciação entre lembrança e percepção, ou seja, para que uma lembrança não redunde em alucinação, o que passa a garantir que a tensão ligada aos estímulos endógenos possa ser descarregada. Vimos como esses campos (lembrança e percepção) estão unidos no processo primário, o que acarreta que as ações reflexas diante da alucinação não satisfaçam aos estímulos endógenos porque não há presença real do objeto. Isso é sentido como desprazer pelo aparelho por que aumenta a quantidade oriunda dos estímulos internos.

Para solucionar esse impasse é necessário que o aparelho disponha de dois recursos. Em primeiro, Freud pensa em uma terceira classe de neurônios $(\omega)$, que são capazes de operar com aspectos qualitativos que formam o que chama consciência. Esses neurônios seriam completamente permeáveis (tal como o 
sistema $\varphi$ ), mas capazes de se apropriar do período da excitação, a característica temporal da quantidade, o que toma um caráter qualitativo. Eles, portanto, podem indicar a realidade (Realitätszeinchen), ou seja, sinalizar ao sistema $\psi$ se o objeto está, ou não, presente na realidade. Isso se faz pela passagem da quantidade de $\omega$ a $\psi$. Mas isso só é possível se o estado de desejo não for muito intenso; caso contrário, o sistema $\psi$ não será capaz de receber essa quantidade de $\omega$ sinalizando a qualidade. Aqui entra o segundo recurso. Para que o estado de desejo não fique muito intenso e não tome os caminhos do trilhamento no sentido dos neurônios $\psi$ do pallium, o que redundaria na ativação do sistema perceptivo, na alucinação e no desprazer, o sistema $\psi$ nuclear deve ser capaz de criar defesas contra o aumento de tensão. Isso é feito por ligações colaterais entre esses neurônios para dividir a tensão, evitar o desprazer e permitir que o sistema $\psi$ possa estar apto a receber o sinal de $\omega$ e realizar a ação específica. A esse complexo do sistema $\psi$ nuclear, Freud chama Ego. Isso leva Freud a dizer que “a precondição necessária destes últimos (processos secundários) é a utilização correta das indicações de realidade, que só se torna possível quando existe inibição por parte do ego" (FREUD, 1895a/1987, p.337).

Em determinada leitura que se origina no “Projeto”, a oposição parcial entre o processo primário e o secundário foi suficiente para que se transformassem essas duas ordens de relações, postuladas por Freud, no suporte para toda uma psicologia adaptacionista. Para tanto, desenhou-se o seguinte quadro de embate entre forças antagônicas: por um lado, o processo primário, como uma forma de funcionamento primitiva do aparelho psíquico, correspondente ao princípio do prazer (princípio da inércia), que não apresenta nenhum compromisso com a realidade e a satisfação das necessidades do humano; por outro, o processo secundário, ordem de funcionamento mais desenvolvida e complexa, correspondente ao princípio de realidade, que não se organiza pela descarga imediata de energia. Ao contrário, faz da capacidade de reserva de energia aquilo que garante a satisfação da necessidade e a boa adaptação do ser humano à realidade que se apresenta, uma vez que é esta realidade que pode oferecer o objeto real de satisfação.

Para tal interpretação, o conceito de ação específica é central para que se estabeleça a diferença entre uma boa adaptação à realidade, com formas eficientes de satisfação psíquica, e uma adaptação ruim, na qual os estímulos de ordem interna não alcançam níveis satisfatórios de descarga. Para exemplificar essa posição, em um texto de 1950, Hartmann propõe que a origem da instância egoica estaria vinculada ao surgimento do processo secundário, na medida que funcionaria como intermediador entre o impulso oriundo das necessidades internas e o mundo externo que pode garantir sua satisfação. Ao ego cumpriria a missão de agir no sentido de considerar as exigências desses dois campos e 
garantir o encontro entre o impulso e seu objeto. Para este tipo de posição, todo o trabalho clínico giraria, então, no sentido de aprimorar essa função egoica, garantindo o bom encontro entre desejo e objeto.

De forma geral, as definições sobre o que seja o conceito de ação específica parecem se ater à eficácia dessa ação, ou seja, sua capacidade de encontrar por meio da atividade no mundo externo o objeto capaz de suprimir a tensão gerada pelo estímulo interno. Uma dessas apresentações do conceito diz:

“Termo utilizado por Freud em alguns de seus primeiros escritos para designar o conjunto do processo necessário à resolução da tensão interna criada pela necessidade: intervenção externa adequada e conjunto das reações pré-formadas do organismo que permitem a realização do ato.”3 (LAPLANCHE \& PONTALIS, 1992, p.4)

Acontece que essa maneira de ler o "Projeto" omite uma série de relações entre o processo primário e o secundário que configuram o escrito de Freud e se equivoca de forma clara no destino dado às considerações que encontramos ali. O esquema desenhado por Freud é bem mais complexo e envolve outros elementos não contemplados por esse tipo de leitura.

O processo primário não pode ser evoluído ao secundário por uma promessa de que um dispositivo mais rústico pudesse passar a outro mais elaborado e de qualidade diferente. Se a experiência de satisfação dá a gênese do processo primário, este, por sua vez, é apoio permanente para o processo secundário, no sentido de fornecer sua sustentação. Dessa maneira, a "ação específica é desencadeada pelo princípio de realidade a serviço do princípio do prazer” (ALBERTI, 1999, p.54).

Para entender melhor essa relação, voltemos a alguns pontos. Indicamos logo no início que a ação específica se relaciona de modo direto à Not des Lebens, à urgência experimentada pelo humano diante de algo de que não consegue se livrar nem resolver. Para Freud esse é o ponto zero da ação específica, e é também o ponto de retorno, como veremos adiante. Mas é também o ponto zero do ser humano, uma vez que essa urgência é associada ao que chama de Hilflosigkeit, o desamparo que aparece no "Projeto" como a condição humana. A essa condição virá se juntar a experiência de satisfação indissociável do "humano ao lado”. Há, portanto, nesse encontro, um tempo reduzido a um instante, e nele se concentram dois eventos bastante importantes. Em primeiro lugar, Freud diz que aí pode ser localizada “a fonte primordial de todos os motivos morais”, e é

\footnotetext{
${ }^{3}$ Interessante lembrar que foi justamente Pontalis o convidado por Lacan a expor suas considerações sobre o "Projeto", quando este último aborda sem reservas o tema da Ética em seu Seminário (1959-1985). As considerações de Lacan sobre a apresentação de Pontalis são muito críticas, como pode ser acompanhado nas aulas de 2/12/59 e 9/12/59.
} 
bastante claro ao associar essa fonte à transformação das reações inespecíficas de descarga, gritos e choros em especial ("inervação da fala”, FREUD, 1895a/1987, p.380), em demanda direcionada ao Nebenmensch para que se obtenha satisfação. É que a ajuda alheia e sua consequente satisfação não poderiam ocorrer, não fosse a interpretação dada ao choro do bebê pelo Nebenmensch. Essa atribuição de sentido, no conjunto da ação específica, transforma o choro em demanda diante do desejo inaugurado. O segundo evento é o próprio desencadeamento do funcionamento do aparelho, quando, a partir de então, funcionará em torno dessa experiência original.

Acontece que esse regime do instante no campo temporal apresenta formas outras de desdobramento no próprio tempo. Enquanto instante, ele é início de um tempo que, por sua vez, deve lhe incorporar em seu pulsar. Isso pode ser observado nos dois eventos relatados. Os motivos morais dos quais fala Freud se referem às relações entre humanos que devem trazer a marca de sua origem, ou seja, do instante em que surge a demanda de satisfação a partir da primeira experiência.

Assim, há um índice primeiro da relação com o outro que deverá ser reestabelecido a cada novo encontro. Isso ocorre da mesma maneira no que toca ao funcionamento do aparelho. O que se coloca em jogo a partir da primeira experiência de satisfação é um funcionamento que, diante da presença daquilo que Freud chamou desejo, visa reencontrar o objeto a cada experiência, em um esforço para conformar os objetos empíricos a este primeiro. Se o próprio modelo do "Projeto" já demonstra isso com clareza, Freud foi ainda mais cristalino em outras passagens de sua obra. Abordando o processo secundário em seu texto de 1925, "Die Verneinung” (A Negativa), nos diz o seguinte a propósito do próprio núcleo desse processo, o "teste de realidade” (que aparece no Projeto como indicação da realidade, como vimos): "Portanto, o objetivo primeiro e imediato do teste de realidade é não encontrar na percepção real um objeto que corresponda ao representado, mas reencontrar tal objeto, convencer-se de que ele está lá” [grifo nosso] (FREUD, 1925a/1987, p.298). Por isso, Lacan nos parece bastante preciso quando considera que:

“tudo o que ocorre aqui apresenta o paradoxo de estar no próprio lugar onde reina o princípio da articulação pela Bahnung, o lugar onde também se produz todo o fenômeno alucinatório da percepção, da falsa realidade à qual o organismo humano é predestinado... Há um grande sistema por trás dessa spezifische Aktion, pois justamente ela não pode corresponder senão ao objeto reachado. Esse é o fundamento do princípio

\footnotetext{
${ }^{4}$ Ver também "Três ensaios sobre a teoria da sexualidade” (FREUD, 1905/1987, p.229), quando diz: "O encontro de um objeto é, na realidade, um reencontro dele".
} 
de repetição em Freud. A essa spezifische Aktion sempre faltará alguma coisa.” (LACAN, 1959/1985, p.56, grifo nosso)

Assim, vemos como Freud nunca sistematizou um modelo no Projeto que pudesse conformar (no sentido de adaptar) o humano a uma realidade exterior a ele, mas antes, que pudesse dar conta da estrutura dessa relação e de como alguma realidade se constitui humana. Assim, no que concerne à ação específica, é evidente que objetos reais são responsáveis pela manutenção da vida, e não era necessário Freud para isso afirmar. A verdadeira questão que parece estar presente no Projeto se refere a como a relação do humano com esses objetos é apoiada e intermediada por outra coisa, que faz — por meio dos mecanismos que já foram descritos antes - com que tais objetos não sejam exatamente o que são. Se fosse diferente disso, que destino poderíamos dar às suas considerações no Projeto sobre a percepção e memória? Ambas mostram, no modelo freudiano, que o humano não é inundado pela realidade de maneira indiferente, mas como, a partir da experiência de satisfação, trilhamentos são constituídos e inauguram um circuito específico de relação com a realidade. Lacan diz:

"No final das contas, sem algo que o alucine enquanto sistema de referência, nenhum mundo da percepção chega a ordenar-se de maneira válida, a constituir-se de maneira humana. O mundo da percepção nos é dado por Freud como que dependendo dessa alucinação fundamental sem a qual não haveria nenhuma atenção disponível." (LACAN, 1959/1985, p.69)

Ou um pouco antes, no mesmo Seminário:

“...temos aqui a noção de uma profunda subjetivação do mundo exterior — alguma coisa tria, cria de tal maneira que a realidade só é entrevista pelo homem, pelo menos no estado natural, espontâneo, de uma forma profundamente escolhida. O homem lida com peças escolhidas da realidade.” (LACAN, 1959/1985, p.63)

Essas duas citações fazem menção direta ao instante original que refere à experiência de satisfação freudiana. Ora, sabemos que propor uma experiência original com um objeto real de satisfação não é necessário para que as coisas se coloquem dessa forma. Ou seja, essa espécie de recurso mitológico freudiano da experiência empírica de completa satisfação original é dispensável para sustentar todas as consequências que o próprio Freud extraiu desse ponto. Como Lacan mostrou, com precisão, o objeto de satisfação é colocado para o sujeito só depois da incidência do simbólico, sem que se tenha a necessidade de presumi-lo empírico. Ele é produto dessa incidência. 
Assim, a despeito dessa diferença sobre a apresentação do estatuto do objeto para Freud e Lacan, podemos encontrar nessa referência à ação específica, para ambos, o instante original no qual se constitui o sujeito e aquilo que marca esse sujeito a partir dessa constituição.

Ou seja, podemos localizar na ação específica as duas modalidades de tempo do sujeito às quais nos referimos aqui. Em primeiro lugar, há a ação específica tomada enquanto instante original do sujeito, tempo em que, naquela relação com o Nebenmensch, o aparelho psíquico ganha sua forma de funcionar, seu circuito próprio, suas Bahnungen, as quais Lacan vai articular diretamente à formação da cadeia significante. Isso é o que dá origem também à segunda modalidade de tempo observada em relação à ação específica. É o tempo de deslizamento e de retorno, e também de repetição, no qual a ação específica se coloca por buscar reencontrar a experiência de satisfação reeditando sempre seus circuitos. É um tempo que se desloca a partir de um ponto inicial, mas que pulsa sempre com a promessa de realizar o momento original. Tempo de reinscrição das Bahnungen: "fundamento do princípio de repetição em Freud", como afirma Lacan. Falamos então sobre duas ações: uma ação específica fundadora, como um ato de constituição, e a ação específica enquanto um pulsar ao longo do tempo. A primeira é uma marca que origina um tempo; a segunda é o deslizamento e a repetição dessa marca em tempos de sucessão.

Se a ação específica constitui o sujeito em seu primeiro tempo, esse só pode ser um sujeito em relação à alteridade, como mostra o Projeto (Nebenmensch). Mas essa alteridade parece ser bastante difusa neste tempo da ação específica. Não é por outra razão que Lacan assimila essa alteridade protagonista na ação específica à Coisa (Das Ding). Ao mesmo tempo que é um ato que implica um sujeito, implica também Das Ding, este ponto de extimidade que encarna a vivência de satisfação pulsional, diz Lacan: “O Ding como Fremde, estranho e podendo mesmo ser hostil num dado momento, em todo caso como um primeiro exterior, é em torno do que se orienta todo o encaminhamento do sujeito" (LACAN, 1959/1985, p.69). Daí o caráter ainda difuso dessa alteridade neste instante. Neste ponto é um ato peculiar porque nele não há endereçamento ao Outro, mas a própria origem do Outro em sua relação com o sujeito. Sujeito e Outro criam e são criados pela experiência original. É, portanto, um ato de criação. Propomos que esse seja o ponto inicial do sujeito: a ação específica na experiência de satisfação original, para Freud; a ação específica como instante do atravessamento do vivente pelo simbólico, para Lacan. ${ }^{5}$

\footnotetext{
${ }^{5}$ Talvez devamos tomar o termo sujeito aqui em uma acepção mais fraca, ou, pelo menos, mais elástica. Fica claro que esse não é um termo freudiano. Mas essa não é a única razão. Também não se trata aqui, ainda, do sujeito que é representado por um significante para outro significante, na definição corrente dada por Lacan. Parece mais que se fala, nesse ins-
} 
Todavia, embora se trate de um ato criativo, ele é inauguração de um ciclo de alienação e repetição. Aqui é o segundo tempo da ação específica, quando o ato quer retornar ao Outro da satisfação. Aqui temos os efeitos do instante original. Em primeiro lugar, a instalação do desejo. O desejo é efeito da ação específica primordial e se desloca pelo tempo que essa ação inaugura, tempo da ação específica em seu segundo tempo. As ações específicas nesse segundo tempo são as atualizações permanentes do desejo — que, para Lacan, é desejo do Outro. Ou seja, desejar é desejar o desejo do Outro. Isso é o que vemos na definição do Projeto. O desejo se relaciona à ação específica a partir de uma busca para reencontrar a experiência de satisfação primeira oferecida pelo Nebenmensch. É, portanto, algo que se reatualiza sempre, mas que também se apresenta por um estado, uma condição, a condição de que alguma Coisa falta:

“Eu quis mostrar-lhes que não existe objeto a não ser metonímico, sendo o objeto do desejo objeto de desejo do Outro, e sendo o desejo sempre um desejo de Outra coisa - muito precisamente, daquilo que falta, a, o objeto perdido primordialmente, na medida em que Freud mostra-o sempre por ser reencontrado." ${ }^{\text {(LACAN, }}$ 1957/1999, p.16)

A demanda também toma seu lugar neste segundo tempo da ação específica. Vimos como a interpretação dada pelo Nebenmensch ao choro reflexo do bebê quando em estado de desamparo, transforma essa "inervação da fala” (como a isso se refere Freud) em demanda que surge em conjunto com o desejo. A demanda é endereçada ao Outro para que se restitua o estado original de satisfação. Demanda que ultrapassa a necessidade, porque, devido às Bahnungen criadas pela experiência original de satisfação, a necessidade já não pode se inscrever como tal, mas somente transformada como pedido de restituição de um objeto que não será nunca mais experienciado de maneira plena, pois os objetos serão sempre pálidos representantes do objeto original. Assim, para Lacan, a demanda se coloca "na base do exercício primordial do significante na expressão do desejo” (LACAN, 1957/1999, p.95). E por essa razão articula a Bahnung do Projeto à cadeia significante. Com efeito, neste segundo tempo da ação específica

\footnotetext{
tante sobre qual referimos, daquilo que Freud definiu como formação do Eu-Prazer (Lust-Ich), uma primeira forma de separação (e formação) entre o Eu e a realidade, em que esta última surge como expulsão da pulsão que será condição para que as primeiras representações se coloquem (FREUD, 1925/1987). Em Lacan, isso se liga mais à noção da incidência de um significante primordial sobre o vivente (LACAN, 1955/2002), também condição necessária (embora não suficiente) para que se forme a cadeia significante.

${ }^{6}$ Como sabemos, esse estatuto puramente metonímico do objeto será revisto por Lacan. Isso se dará por uma separação clara entre o objeto imaginário - $\varphi$ e o objeto pequeno a. Nessa citação encontramos a primeira acepção.
} 
podemos observar a cadeia em funcionamento. O objeto perdido como Coisa funciona como sustentação do desejo, ou seja, põe em movimento a cadeia para a realização infinita do desejo nos desfiladeiros do significante:

"O desejo se situa na dependência da demanda - a qual, por se articular em significantes, deixa um resto metonímico que corre debaixo dela, elemento que não é indeterminado, que é uma condição ao mesmo tempo absoluta e impegável, elemento necessariamente em impasse, insatisfeito, impossível, desconhecido, elemento que se chama desejo." (LACAN, 1964/1985, p.146)

Neste tempo o significante representa o sujeito para outro significante, o que faz do sujeito efeito da cadeia. Esse é o tempo do simbólico neste segundo tempo da ação específica. Tempo de um sujeito sujeitado ao significante, à sua diacronia e retroação.

Mas há também o tempo do real neste segundo tempo da ação específica. Esse tempo, não o encontramos no sujeito em relação à cadeia, mas à fantasia. Se, por um lado, na fantasia há relação do sujeito ao objeto enquanto realização (infinita) do desejo, por outro há também relação com o objeto enquanto mais de gozar. Nesse sentido, ao contrário do deslizamento do sujeito na cadeia significante, há uma fixação da posição do sujeito na fantasia indicada por Lacan como aquilo "que se reencontra sempre no mesmo lugar", posição do real (LACAN, 1959/1985, p.90). Trata-se da monotonia da fantasia que, apesar de poder se apresentar de muitas formas variadas, se refere sempre a uma fantasia fundamental, que é uma montagem do sujeito que busca um objeto para o desejo. A essa estática corresponde a expressão de Lacan que é o "instante da fantasia”. Assim, a fantasia corresponde ao tempo do instante na ação específica. Instante do primeiro tempo da ação específica e da repetição desse tempo no segundo tempo da ação específica.

Por fim, resta ainda a transferência. Parece-nos possível reconhecer dois tempos da transferência nos dois tempos propostos por nós da ação específica. O primeiro tempo é o da instalação da transferência, tempo de origem do sujeito em relação ao Outro, da demanda e do desejo. Com Freud, dizemos que a transferência é o deslocamento das relações primordiais do sujeito com o semelhante em que as marcas dessas relações serão atualizadas com outros. São as marcas da demanda inaugurada pela ação específica que são atualizadas. Assim, o segundo tempo é o da transferência enquanto a própria atualização da realidade inconsciente. E nesse segundo tempo podemos reconhecer as duas dimensões da transferência. Em primeiro lugar, a ordem dinâmica do deslocamento: a transferência é deslocada de um para outro. O que foi vivido como experiência original é permanentemente deslocado no encontro com os outros 
em experiências atuais. Em segundo lugar, vemos a dimensão da repetição da transferência. Embora haja deslocamento, é sempre a mesma ordem de relação que se atualiza. Nesse sentido, na ação específica, embora encontremos a origem da transferência - o que, apesar de se considerar um ato de criação, é um ato de criação a partir do nada - encontramos também a vertente forte de repetição da transferência, como "reino das Bahnungen... como fundamento do princípio de repetição em Freud” (LACAN, 1959/1985, p.56).

Assim, como tentamos desenvolver, a exploração da ideia de ação específica em Freud indica uma consonância reveladora com noções importantes do ensino de Lacan, tais como a constituição do sujeito, o circuito da demanda, a montagem fantasmática, o encadeamento do desejo e a operação da transferência. Mostramos como essa aproximação foi notada e desenvolvida pelo próprio Lacan em seu seminário sobre a “Ética da Psicanálise”. Todavia, pensamos que outros desdobramentos possíveis dessa relação não foram por ele abordados de forma explícita. Então, aqui buscamos apenas apontar alguns deles. Mas o que nos parece mais importante é que a própria construção dessas noções em Lacan não seria possível sem aquilo que podemos encontrar no núcleo do conceito de ação específica, na ideia trabalhada de que o objeto que essa ação visa não pode ser encontrado em objetos empíricos. Ou seja, não pode ser encontrado, senão através de um reencontro montado a partir da cena fantasmática. Assim, a ação específica, ao invés de garantir um objeto ao desejo, manifesta a própria estrutura da inadequação dos objetos empíricos ao desejo. Esse ponto é crucial para a direção da cura em psicanálise, mas não poderemos esclarecer todas as suas implicações aqui, o que requisitaria outro artigo. De qualquer maneira, para nos atermos com brevidade apenas à transferência, uma clínica alicerçada na promessa de restituição do objeto perdido a partir de uma relação mais evoluída com a realidade (suplantando o processo primário pelo secundário), ignorando a letra de Freud, só faz, na verdade, petrificar a transferência na mesmice da repetição sintomática. Pois não faz outra coisa que desconsiderar que é a própria falta de objeto, que se pode operar em transferência, que permite ao sujeito se reposicionar na relação com seu mal-estar a partir de seu desejo que se coloca desde o Outro.

Recebido em 9/3/2009. Aprovado em 22/6/2009. 


\section{REFERÊNCIAS}

ALBERTI, S. (1999) Esse sujeito adolescente. Rio de Janeiro: Rios Ambiciosos. DICIONÁRIO PORTUGUÊS-ALEMÃO. (1983) Porto: Porto.

FREUD, S. (1987) Edição standard das obras psicológicas completas de Sigmund Freud. Rio de Janeiro: Imago.

(1895a) "Projeto para uma psicologia científica”, v.I, p.303-409.

(1895b) "Rascunho k — as neuroses de defesa”, v.I, p.241-249.

(1895c) "Sobre os fundamentos para destacar da neurastenia uma síndrome específica denominada neurose de angústia”, v.III, p.89-114. (1905) “Três ensaios sobre a teoria da sexualidade”, v.VII, p.123-250.

(1915a) “Repressão”, v.XIV, p.165-182.

(1915b) "O instinto e suas vicissitudes”, v.XIV, p.129-162.

(1925) “A negativa”, v.XIX, p.293-300.

(1930) “O mal-estar na civilização”, v.XXI, p. 75-171.

HANS, L. (1996) Dicionário comentado do alemão de Freud. Rio de Janeiro: Jorge Zahar.

HARTMANN, H. (1950) Comments on the Psychoanalytic Theory of the Ego, in Psychoanalytic Study of the Child,v. 5, New Haven: Yale Child Study Center, p.74-96.

LACAN, J. (1955/2002) O Seminário Livro 3, As psicoses. Rio de Janeiro: Jorge Zahar.

(1957/1999) O Seminário Livro 5, As formações do inconsciente. Rio de Janeiro: Jorge Zahar.

(1959/1985) O Seminário Livro 7, Aética da psicanálise. Rio de Janeiro: Jorge Zahar.

(1964-1985) O Seminário Livro 11, Os quatro conceitos fundamentais da psicanálise. Rio de Janeiro: Jorge Zahar.

LAPLANCHE, J. (1998) Vocabulário de Psicanálise. São Paulo: Martins Fontes.

TOCHTROP, L. (1968) Dicionário alemão-português. Porto Alegre: Globo.

Ronaldo Torres

ronaldotorres@usp.br 